\title{
THE SPECIFICITY OF EXTRACELLULAR GLYCOPROTEIN COMPLEXES IN MEDIATING CELLULAR ADHESION ${ }^{1}$
}

\author{
DAVID SCHUBERT ${ }^{2}$ AND MONIQUE LACORBIERE
}

The Salk Institute, San Diego, California 92138

Received August 14, 1981; Revised September 25, 1981; Accepted September 25, 1981

\begin{abstract}
Complexes containing glycoproteins and glycosaminoglycans were released into the culture medium by both smooth and skeletal muscle cells. The particles, termed adherons, from three smooth muscle cell lines promoted cell-substratum adhesion of a clonal sympathetic nerve cell line, PC12. In contrast, the glycoprotein complexes from three skeletal muscle preparations inhibited the adhesion of PC12 cells to Petri dish surfaces. The skeletal muscle adherons all sedimented in calcium-free sucrose gradients with an $S$ value of 16 , while the smooth muscle particles had a sedimentation value of 12 . Although both classes of adherons contained fibronectin and collagen, hyaluronic acid was present only in those from skeletal muscle. An antiserum prepared against skeletal muscle adherons blocked myoblast adhesion to skeletal muscle adherons but did not alter PC12 adhesion to smooth muscle adherons. These data suggest that the glycoprotein complexes released by muscle have some intrinsic specificity with respect to their ability to mediate cellular adhesion.
\end{abstract}

Extracellular macromolecules have been implicated in several aspects of cellular adhesion. Material purified from growth-conditioned media of chick neural retina cultures mediates cell-cell interactions between cells cultured from this tissue (McClay and Moscona, 1974; Thiery et al., 1977), and molecules released from fibroblast-like cells adhere to the surface of the culture dish and promote cell-substratum adhesion (Moore, 1976; Millis and Hoyle, 1978). Embryonic heart cells also release trypsin-sensitive molecules which associate with the culture dish, stimulate the adhesion of neural filopodia, and induce neurite outgrowth (Collins, 1980). Finally, a macromolecular complex containing glycoproteins and glycosaminoglycans (GAGs) was isolated recently from the culture medium of skeletal muscle cells. This particle shares some characteristics of the adhesionmediating activities listed above (Schubert and LaCorbiere, 1980a). It stimulates cell-cell and cell-substratum adhesion of myoblasts, while it inhibits the adhesion of the PC12 clone of sympathetic-like nerve cells. The adhesion-modulating activity migrates with a sedimentation velocity of $16 \mathrm{~S}$ in calcium-free sucrose gradients; it aggregates in the presence of calcium ions. The $16 \mathrm{~S}$ myoblast particles are composed of glycosaminoglycans and several proteins, including collagen and fibronectin.

\footnotetext{
' This work was supported by grants from the Muscular Dystrophy Association of America, Inc. and the National Institutes of Health.

${ }^{2}$ To whom correspondence should be addressed at The Salk Institute, P.O. Box 85800, San Diego, CA 92138.
}

This adhesion-mediating particle has been termed an adheron.

Since sympathetic nerves normally innervate smooth muscle but not skeletal muscle, the observation that 16 $S$ particles from $L 6$ skeletal muscle cells block the adhesion of sympathetic nerve-like cells is not surprising. Moreover, these observations present the opportunity to ask if there is any specificity with respect to the adhesion of sympathetic-like nerve cells to surfaces coated with adherons from different types of muscle. If these particles reflect the specificity of the nerve-muscle interaction, then adherons from skeletal muscle should block the cellsubstratum adhesion of sympathetic nerve cells, while smooth muscle adherons should promote cell-substratum adhesion of sympathetic cells. The following data describe adherons from several clonal skeletal and smooth muscle cell lines and show that the expected type of adhesive specificity occurs in culture between a sympathetic nerve-like cell line, PC12, and adheron-coated substrata from smooth and skeletal muscle cells.

\section{Materials and Methods}

Cells and culture. The L6 myoblast line was obtained from Yaffe (1968) and maintained in $10 \%$ fetal calf serum in Dulbecco's modified Eagle's medium (DME). The PC12 clone was obtained from Greene (Greene and Tischler, 1976) and grown in the same medium plus $10 \%$ fetal calf serum and $5 \%$ horse serum. Two smooth muscle lines, A10 and A7, were isolated from embryonic rat aorta (Kimes and Brandt, 1976). A third, $\mathrm{BC}_{3} \mathrm{H} 1$, was derived 
from a mouse brain tumor (Schubert et al., 1974a). The skeletal muscle line B44 was obtained from a rat tumor (Schubert et al., 1974b). Primary cultures from rat thigh muscle were prepared according to Bloch and Geiger (1980).

Protein and glycosaminoglycan assays. Cells were labeled with $\left[{ }^{3} \mathrm{H}\right]$ leucine and tube gel electrophoresis was done in gels containing $6 \%$ acrylamide and $0.1 \% \mathrm{Na}$ $\mathrm{DodSO}_{4}$ as described (Schubert and LaCorbiere, 1980a). GAG analysis was carried out by labeling cells with $\left[{ }^{3} \mathrm{H}\right]$ glucosamine or $\left[{ }^{35} \mathrm{~S}\right]$ sulfate, chromatographing the sample on a DEAE-cellulose column (Underhill and Keller, 1976), and identifying the GAGs in the individual peaks by enzymatic methods (Saito et al., 1968). Streptomyces hyaluronidase (B grade, Calbiochem, San Diego, CA) was used at 50 units $/ \mathrm{ml}$ for $24 \mathrm{hr}$ at $37^{\circ} \mathrm{C}$. Chondroitinase $\mathrm{ABC}$ and $\mathrm{AC}$ (Miles Laboratories, Elkhart, IN) were used at $0.5 \mathrm{unit} / \mathrm{ml}$ for $24 \mathrm{hr}$ at $37^{\circ} \mathrm{C}$. GAG breakdown was monitored by column chromatography in Sephadex G-50. Hydroxyproline was determined by labeling cells with $\left[{ }^{14} \mathrm{C}\right]$ proline. The fractions of interest were isolated, hydrolyzed in $6 \mathrm{M} \mathrm{HCl}$, and chromatographed on an amino acid analyzer, and the radioactivity in the 4-hydroxyproline and proline peaks was determined.

Preparation of conditioned medium and substrateattached material. Conditioned medium was prepared from exponentially dividing cells by washing the cells twice in serum-free 4-(2-hydroxyethyl)-1-piperazine-ethanesulfonic acid (HEPES)-buffered DME medium and incubating the cells in the same medium for $15 \mathrm{hr}$ at $37^{\circ} \mathrm{C}$. To prepare substrate-attached material (SAM)coated dishes, growth-conditioned medium was placed in 35-mm plastic Petri dishes (Falcon) for $18 \mathrm{hr}$, and then the dishes were washed twice with $0.5 \mathrm{~mm}$ ethylene glycol bis $\left(\beta\right.$-aminoethyl ether)- $N, N, N^{\prime}, N^{\prime}$-tetra-acetic acid (EGTA), three times with water, and once with HEPES medium (Culp, 1974). After the final wash, $2 \mathrm{ml}$ of HEPES medium containing $0.2 \%$ bovine serum albumin was added.

Adhesion assays. To assay cell-substratum adhesion, early stationary phase $\mathrm{PC1} 2$ cells were labeled with $\left[{ }^{3} \mathrm{H}\right]$ leucine $(5 \mu \mathrm{Ci} / \mathrm{ml})$ for $15 \mathrm{hr}$. The cells were washed three times with HEPES medium containing $0.2 \%$ albu$\mathrm{min}$, and $0.2-\mathrm{ml}$ aliquots were pipetted into $35-\mathrm{mm}$ SAMcoated plastic Petri dishes containing $2 \mathrm{ml}$ of the same medium. At the indicated times, the dishes were swirled 10 times, the medium was aspirated, and the remaining attached cells were dissolved in Triton X-100 and their isotope content was determined. The data were plotted as the fraction of input cells that adhered as a function of time. Variation between duplicates was less than $5 \%$.

Preparation of antiserum. L6 cells were grown in 100. $\mathrm{mm}$ tissue culture dishes and serum-free growth-conditioned medium was prepared as described above. The conditioned medium then was centrifuged at $20,000 \times g$ for $15 \mathrm{~min}$ and the supernatant was centrifuged at 100,000 $\times g$ for $3 \mathrm{hr}$. The pellet was resuspended in saline. For each injection, $100 \mu \mathrm{g}$ of particulate material in saline was mixed with an equal volume of complete Freund's adjuvant and injected subcutaneously into six spots on the backs of white New Zealand female rabbits. After four $100-\mu \mathrm{g}$ injections equally spaced over 6 weeks, the rabbits were bled and the serum was used in these experiments. IgG was purified by DEAE chromatography (Garvey et al., 1977) and monovalent $\mathrm{Fab}^{\prime}$ fragments were prepared according to Brackenbury et al. (1977).

\section{Results}

Specificity of adheron-mediated adhesion. When isotopically labeled PC12 sympathetic nerve-like cells were plated into plastic Petri dishes containing HEPESbuffered tissue culture medium and $0.2 \%$ bovine serum albumin (BSA), the majority of the input cells adhered to the culture dish within $1 \mathrm{hr}$ (Fig. 1). However, if PC12 cells were plated into Petri dishes in which L6 skeletal muscle myoblast cells were grown and subsequently removed by EGTA or into dishes which had been exposed to L6 serum-free growth-conditioned medium, adhesion to the culture dish surface was inhibited (Fig. 1). Exposure of culture dishes to cells or to growth-conditioned medium leaves macromolecules, termed substrate-attached material (SAM), on the culture dish substratum. The adsorbed molecules mediate cell-substratum adhesion (Schubert and LaCorbiere, 1980a, b). If the inhibition of PC12 adhesion to culture dishes is a property of SAM produced by all skeletal muscle cells rather than a

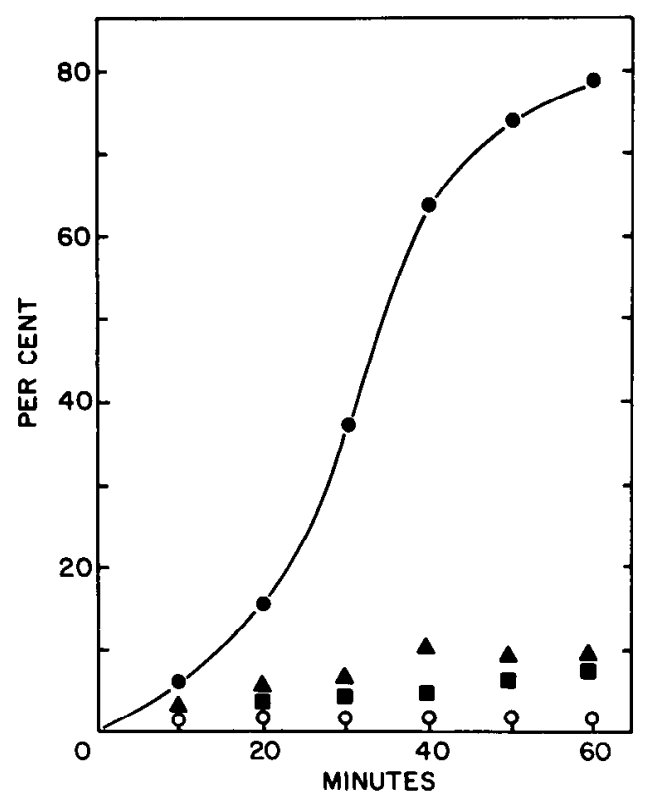

Figure 1. Kinetics of adhesion of $\mathrm{PC} 12$ cells to SAM prepared from skeletal muscle cell growth-conditioned medium. Exponentially growing L6 or B44 myoblasts at a cell density of $5 \times$ $10^{5}$ cells $/ 60-\mathrm{mm}$ culture dish, or confluent primary rat thigh muscle cultures, were incubated overnight in serum-free HEPES medium. The growth-conditioned medium then was placed in $35-\mathrm{mm}$ Petri dishes overnight at $37^{\circ} \mathrm{C}$ and the resultant SAM-coated dishes were washed. Exponentially dividing PC12 cells were isotopically labeled, washed, and plated at 3 $\times 10^{5}$ cells $/$ dish into the SAM-coated dishes containing $2 \mathrm{ml}$ of HEPES medium and $0.2 \%$ BSA. The data are presented as the percentage of input cells that adhered at each time point. Quantitatively similar results were obtained when $2 \times 10^{5}$ muscle cells were grown on each dish and removed by EGTA before the adhesion assay was done (Schubert and LaCorbiere, 1980b). Adhesion to new Petri dishes; O, L6 SAM-coated dishes; $\boldsymbol{\Lambda}$, primary skeletal muscle SAM; $\mathbf{D}$, B44 SAM. 
unique property of the L6 clone, then SAM from other skeletal muscle preparations should have the same effect. Figure 1 shows that SAM prepared from growth-conditioned media of another rat skeletal muscle cell line (B44) and from primary cultures of rat thigh muscle also inhibit the adhesion of PC12 cells to Petri dishes.

To test the ability of substrate-attached material to stimulate the adhesion of PC12 cells to a substratum, assay conditions were required which reduced the adhesiveness of PC12 cells to the Petri dishes. This can readily be accomplished by varying the concentration of BSA used in the assay medium, for the adhesion of these cells is a linear function of BSA concentration between 0 and $0.4 \%$ BSA (Fig. 2). By using a BSA concentration of $0.3 \%$, it was possible to measure both increases and decreases in cell-substratum adhesion accurately.

If the observation that SAM from skeletal muscle decreases the affinity of sympathetic-like nerve cells to a substratum is a reflection of a role of SAM in nervemuscle interactions, then SAM from smooth muscle, which is normally innervated by sympathetic nerves, should stimulate cell-substratum adhesion. Figure 3 shows the adhesion kinetics of PC12 cells to Petri dishes coated with SAMs from three independently isolated smooth muscle cell lines- $\mathrm{BC}_{3} \mathrm{H} 1, \mathrm{~A} 10$, and $\mathrm{A} 7$. SAM from all three cell lines stimulated the adhesion of PC12 cells; SAMs from the skeletal muscle preparations again inhibited adhesion. The effect of SAMs from a variety of other cell lines, including nerve, glia, plasmacytes, pituitary cells, and fibroblasts, was tested also; all increased the cell-substratum adhesion of $\mathrm{PCl} 2$ cells to varying

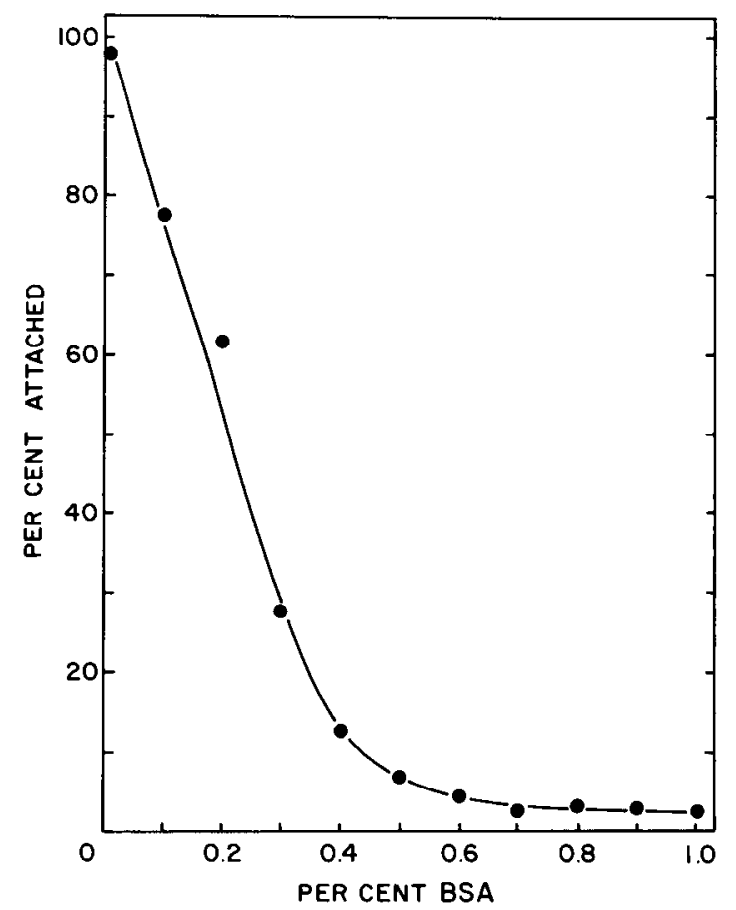

Figure 2. Adhesion of $\mathrm{PC1} 12$ cells to Petri dishes as a function of BSA concentration. Isotopically labeled PC12 cells were plated into new Petri dishes containing different concentrations of BSA in HEPES medium. The percentage of adhering input cells at $40 \mathrm{~min}$ is plotted as a function of the percent $(w / v) \mathrm{BSA}$ used in the adhesion assay. The data are the average of duplicate determinations, which varied less than $10 \%$

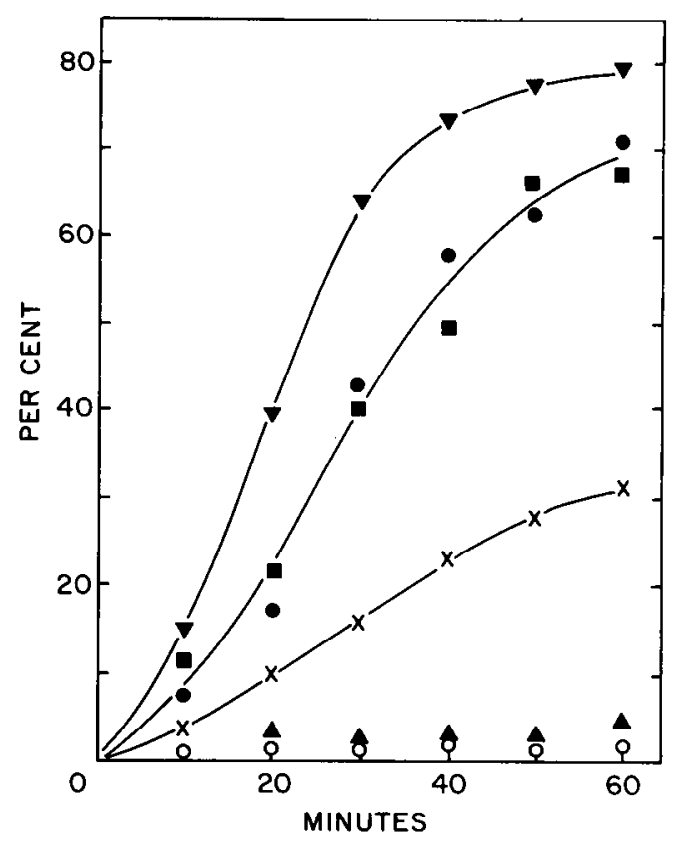

Figure 3. Effect of skeletal and smooth muscle SAMs on PC12 cell-substratum adhesion. Isotopically labeled PC12 cells and the various SAMs were prepared as described in Figure 1. The conditions were the same except that the adhesion medium contained 0.3\% BSA. $\times$, Petri alone; $\nabla, \mathrm{BC}_{3} \mathrm{Hl}$ SAM;, $\mathrm{Al0}$ SAM; D, A7 SAM; $\triangle$, B44 SAM; O, L6 SAM.

extents. Therefore, of the cell types tested, only SAM derived from skeletal muscle cells inhibited the adhesion of $\mathrm{PC} 12$ cells.

Since proteins, such as BSA, alter cell-substratum interactions in a concentration-dependent manner (Fig. 2 ), it is possible that the results shown in Figure 3 result from a concentration-dependent effect of the skeletal and smooth muscle SAMs and adheron particles. For example, more of the same adhesion-modulating material may be released by skeletal muscle than smooth muscle, and it may be adhesion inhibiting at high concentrations and adhesion promoting at low concentrations. To rule out this possibility, serum-free conditioned growth media were prepared from $\mathrm{L} 6$ and $\mathrm{BC}_{3} \mathrm{H} 1$ cells and the media were centrifuged at $100,000 \times g$ to isolate the adhesionmediating particles. These then were diluted to various concentrations in HEPES medium in Petri dishes, and the dishes were incubated overnight at $37^{\circ} \mathrm{C}$ and extensively washed. By including isotopically labeled material, it was shown that all of the input material adhered to the Petri dishes. The kinetics of PC12 adhesion to the particle-coated dishes then were determined over a period of $1 \mathrm{hr}$, and the percentage of the adhered input cells after $30 \mathrm{~min}$ incubation was plotted as a function of adheron concentration. Rat cold-insoluble globulin (CIG) was treated the same way and served as a control since it inhibits the cell-substratum adhesion of PC12 cells (Schubert and LaCorbiere, 1980a). Figure 4 shows that increasing concentrations of adherons from $\mathrm{BC}_{3} \mathrm{H} 1$ smooth muscle cells increased the fraction of adhering cells in a concentration-dependent manner, while adherons from the L6 skeletal muscle cells and CIG decreased the adhesion of PC12 cells.

An additional criterion for the specificity of an adhe- 


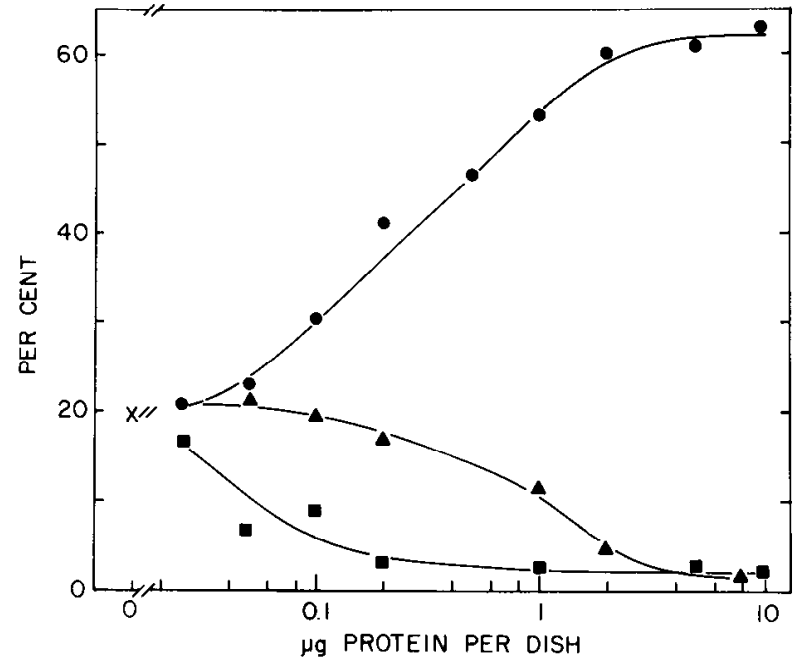

Figure 4. Adhesive response of $\mathrm{PC} 12$ cells to adherons from $\mathrm{L} 6$ and $\mathrm{BC}_{3} \mathrm{H} 1$ and to rat serum CIG. Serum-free growthconditioned medium from approximately $5 \times 10^{8} \mathrm{~L} 6$ and $\mathrm{BC}_{3} \mathrm{H} 1$ cells was centrifuged at $100,000 \times g$ for $2 \mathrm{hr}$ to pellet the adhesion-mediating particles. These particles then were resuspended in HEPES medium and incubated at various concen. trations overnight on Petri dishes. CIG from rat serum also was incubated in Petri dishes. All of the $\mathrm{L} 6$ and $\mathrm{BC}_{3} \mathrm{H} 1$ particles attached to the Petri dishes as shown by the binding of isotopically labeled material included in some of the samples. The following day, the dishes were washed twice with HEPES medium and the adhesion of PC12 cells was determined at 15min intervals over a period of $1 \mathrm{hr}$ as described in Figure 1. A smooth curve was drawn through the adhesion curves for each condition, and the percentage of the adherent input cells was determined at $30 \mathrm{~min}$. This percentage is plotted against the amount of protein in the particles or CIG added to the culture dish. The adhesion of $\mathrm{PC} 12$ cells to Petri dishes alone at $30 \mathrm{~min}$ was $20 \%$. $\mathbf{L} 6$ particle;, $\mathrm{BC}_{3} \mathrm{H} 1$ particle; $\boldsymbol{\Delta}$, rat $\mathrm{CIG}$.

sive interaction is the ability of an antiserum to block selectively one subset of a group of related adhesions. Therefore, if the smooth muscle adheron which promotes the adhesion of PC12 cells is distinct from that released from skeletal muscle, an antiserum prepared against the skeletal muscle adheron should not block adhesion promoted by the smooth muscle particle. An antiserum was induced in rabbits against $\mathrm{L} 6$ particles, and the monovalent $\mathrm{Fab}^{\prime}$ fragments were prepared. Figure 5 shows that anti-L6 adheron inhibited the adhesion of L6 myoblasts to $\mathrm{L} 6$ adherons but that it did not block the adhesion of $\mathrm{PC} 12$ cells to $\mathrm{BC}_{3} \mathrm{H} 1$ adherons. The anti-L6 $\mathrm{Fab}^{\prime}$ molecules also partially neutralize the ability of $\mathrm{L} 6$ adherons to inhibit the adhesion of PC12 cells to Petri dishes. Doubling the $\mathbf{F a b}^{\prime}$ concentration did not increase this neutralization. Similar results were obtained using adherons from another skeletal muscle cell line, B44. By using isotopically labeled adherons, it was shown that the antibody does not block adhesion by simply releasing L6 particles from the plastic substratum (D. Schubert and $\mathrm{M}$. LaCorbiere, unpublished results).

Glycosaminoglycans appear to play a critical role in the cell-substratum adhesion of some cell types, for the adhesion of a variant muscle cell line to different SAMcoated substrata was inhibited completely by low concentrations of some GAGs (Schubert and LaCorbiere,
$1980 \mathrm{~b})$. The specificity of inhibition was unique for each substratum, for one type of GAG inhibited binding to one surface, while another GAG inhibited binding to another. The GAGs presumably compete for binding sites on the cell surface or in the particle-coated surface which are involved in the adhesion reaction. If it is generally true that the type of GAGs which inhibit is specific for each class of cell-substratum interaction, then the GAG inhibition profiles for the adhesion between PC12 cclls and the various smooth muscle SAMs should closely resemble each other. They also should be distinct from those of the PC12 cell-skeletal muscle SAM interaction. To examine this possibility, Petri dishes were coated with the adherons from the skeletal muscle lines $\mathrm{L} 6$ and $\mathrm{B} 44$ and the smooth muscle lines $\mathrm{BC}_{3} \mathrm{HI}, \mathrm{Al0}$, and A7. The adhesion of PC12 cells to these substrata then was determined in the presence of varying concentrations of GAGs. The concentration of a GAG which produced $50 \%$ inhibition of cell binding to smooth muscle particles is shown in Table I. The binding of PC12 cells

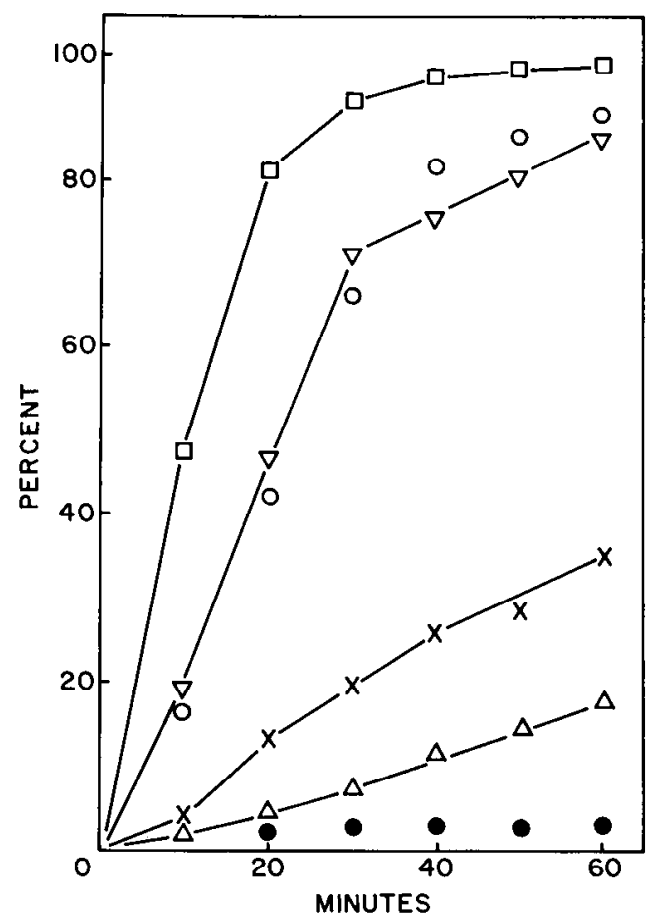

Figure 5. Effect of anti-L6 adheron on adhesion. Monovalent anti-L6 adheron F.ab' fragments were added at $1 \mathrm{mg} / \mathrm{ml}$ to assay dishes containing the indicated substrata. One hour later, cells were added and the kinetics of adhesion were determined as described in Figure 1. Isotopically labeled L6 myoblasts were dissociated with $5 \times 10^{-4} \mathrm{M}$ EGTA in calcium- and magnesiumfree HEPES medium for $30 \mathrm{~min}$ at $37^{\circ} \mathrm{C}$. The resultant single cells were washed twice with HEPES/BSA and immediately used in the adhesion assay. $\times, \mathrm{PC} 12$ cells on new Petri dishes with pre-bleed anti-L6 adheron $\mathrm{Fab}^{\prime} ; \nabla, \mathrm{PC} 12$ cells on $\mathrm{BC}_{3} \mathrm{H} 1$ SAM-coated dishes with pre-bleed Fab'; O, PC12 cells on $\mathrm{BC}_{3} \mathrm{H} 1$ SAM-coated dishes with anti-L6 adheron Fab'; $\square$, L6 cells on L6 SAM-coated dishes with pre-bleed $\mathrm{Fab}^{\prime} ; \triangle, \mathrm{PC} 12$ cells on L6 SAM-coated dishes with anti-L6 adheron Fab'; L6 cells on L6 SAM-coated dishes with anti-L6 adheron Fab'. - also represents L6 cells on Petri dishes alone plus normal rabbit serum $\mathrm{Fab}^{\prime}$ and PC12 cells on L6 SAM-coated dishes with pre-bleed $\mathrm{Fab}^{\prime}$. Adhesion was less than $5 \%$ of the input cells in both cases. 
TABLE I

Inhibition of PC12 adhesion to various cell-derived substrata by GAGs Adherons from conditioned medium were prepared and the kinetics of $\mathrm{PC} 12$ adhesion were determined as in Figure 1. For each concentration of carbohydrate, the percentage of input cells attached to the dish was determined at 10-min intervals over a 1-hr period. From these data, the percentages of input cells attached at 30 min were determined and plotted against the carbohydrate concentration. The concentration of carbohydrate that gave $50 \%$ inhibition is presented. The concentrations are shown in terms of the molarity of glucuronic acid, assuming it is a free molecule.

\begin{tabular}{lcccc}
\hline \multirow{1}{*}{\multicolumn{1}{c}{ Reagent }} & \multicolumn{4}{c}{ Cell Lines } \\
\cline { 2 - 5 } & $\mathrm{BC}_{3} \mathrm{H} 1$ & $\mathrm{~A} 10$ & $\mathrm{~A} 7$ & $\begin{array}{c}\text { Petri } \\
\text { Alone }\end{array}$ \\
\hline Chondroitin sulfate A & $>10^{-3}$ & $>10^{-3}$ & $>10^{-3}$ & $1 \times 10^{-3}$ \\
Chondroitin sulfate B & $>10^{-3}$ & $>10^{-3}$ & $>10^{-3}$ & $1 \times 10^{-3}$ \\
Chondroitin sulfate C & $>10^{-3}$ & $>10^{-3}$ & $>10^{-3}$ & $1 \times 10^{-3}$ \\
Heparin & $1 \times 10^{-8}$ & $3 \times 10^{-8}$ & $1 \times 10^{-8}$ & $1 \times 10^{-3}$ \\
Heparan sulfate & $5 \times 10^{-8}$ & $4 \times 10^{-8}$ & $2 \times 10^{-8}$ & $1 \times 10^{-3}$ \\
Hyaluronic acid & $3 \times 10^{-4}$ & $1 \times 10^{-3}$ & $1 \times 10^{-3}$ & $2 \times 10^{-4}$ \\
\hline
\end{tabular}

to adherons of all three smooth muscle cell lines was inhibited effectively by low concentrations of heparin and heparan sulfate and less effectively by hyaluronic acid. In contrast, none of the GAGs tested at $10^{-3} \mathrm{M}$ neutralized the inhibition of PC12 binding to Petri dishes by particles from L6 or B44 skeletal muscle.

To understand the mechanisms responsible, the adhesive differences between smooth muscle and skeletal muscle adherons, their structure, and composition must be defined. Three parameters were examined-size, protein composition, and GAG content.

Size of skeletal and smooth muscle adherons. The activity released into the culture medium of L6 cells which inhibited the adhesion of PC12 cells to culture dish substrata sedimented as a $16 \mathrm{~S}$ particle in calciumfree sucrose gradients (Schubert and LaCorbiere, 1980a). If the $16 \mathrm{~S}$ particles are used universally in muscle adhesion, then the skeletal muscle adherons should be the same in all skeletal muscles. To assay for the $16 \mathrm{~S}$ myoblast particle in an additional skeletal muscle myoblast line (B44) and in primary cultures, cells were incubated for $18 \mathrm{hr}$ in serum-free medium with $\left[{ }^{35} \mathrm{~S}\right]$ sulfate, which labels sulfated GAGs. The conditioned media were centrifuged at $100,000 \times g$ for $2 \mathrm{hr}$, washed twice, and resuspended in $0.01 \mathrm{M}$ HEPES, $\mathrm{pH}$ 7.1. About half of the sulfated GAGs, which were released into the culture medium were recovered in the $100,000 \times g$ pellet. The samples then were sedimented into 5 to $20 \%$ sucrose gradients. The ${ }^{35} \mathrm{SO}_{4}$ label defined a peak that sedimented about one-third of the way into the gradient with a sedimentation value of $16 \mathrm{~S}$ relative to marker ribosomal RNA (Fig. 6A). When the ability of each gradient fraction of the unlabeled material to mediate cell-substratum adhesion was assayed, a decrease in adhesion of PC12 cells was affected only by the gradient fractions that coincided with the presence of the isotope. Thus, B44 releases a particle of the same sedimentation velocity and adhesive properties as that of $\mathrm{L} 6$. The adhesionmediating material released from rat skeletal muscle primary cultures also sediments at $16 \mathrm{~S}$ (D. Schubert and M. LaCorbiere, unpublished result). When the experiment was repeated with the $\mathrm{BC}_{3} \mathrm{H} 1$ and $\mathrm{A} 10$ smooth

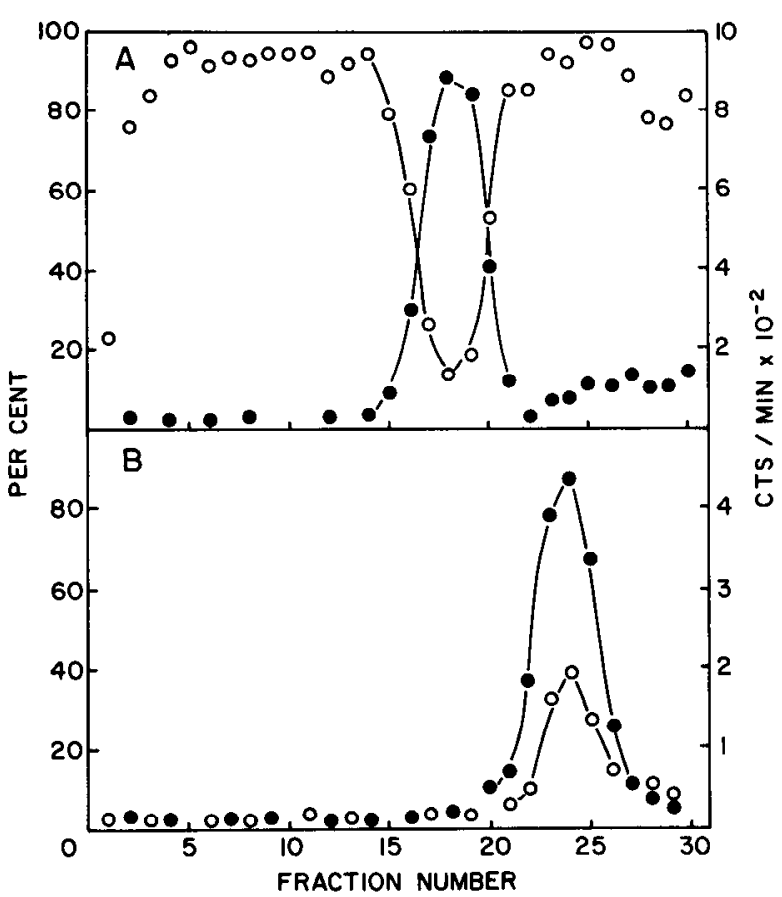

Figure 6. Co-sedimentation of muscle GAGs and adhesion activities in sucrose gradients. $\mathrm{B} 44$ and $\mathrm{BC}_{3} \mathrm{H} 1$ cells were labeled with ${ }^{35} \mathrm{SO}_{4}$ in serum-free medium $\left(5 \times 10^{6}\right.$ cells) or were incubated in serum-free medium alone $\left(2 \times 10^{7}\right.$ cells $)$. After $18 \mathrm{hr}$, the conditioned media were centrifuged at $100,000 \times g$ for $2 \mathrm{hr}$. The two $100,000 \times g$ pellets then were centrifuged for $18 \mathrm{hr}$ at $35,000 \mathrm{rpm}$ at $4^{\circ} \mathrm{C}$ in an SW 41 Beckman rotor into 5 to $20 \%$ linear sucrose gradients containing $0.01 \mathrm{~m}$ HEPES buffer $(\mathrm{pH}$ 7.1). The isotope data are presented as counts per min per fraction. Each gradient fraction with unlabeled cellular material was diluted into HEPES medium and incubated in Petri dishes overnight at $37^{\circ} \mathrm{C}$. The following day, the adhesion of isotopically labeled $\mathrm{PC} 12$ cells was determined and these data are presented as the percentage of input cells that adhered at 40 min. The top of the gradient is at the right. Greater than $92 \%$ of the input isotope was recovered on the gradient; the remainder pelleted. $A$ :,${ }^{35} \mathrm{SO}_{4}$-labeled $\mathrm{B} 44$ particle; $\bigcirc$, adhesion of PC12 cells. $B$ :,${ }^{35} \mathrm{SO}_{4}$-labeled $\mathrm{BC}_{3} \mathrm{H1}$ particle; $O$, adhesion of PC12 cells.

muscle cell lines, all of the smooth muscle adhesionpromoting activity again was removed from the growthconditioned medium by centrifugation at $100,000 \times g$ for $2 \mathrm{hr}$. However, both the sulfate-labeled material and the adhesion-promoting activities sedimented more slowly in the sucrose gradient (Fig. $6 B$ ). Similar results were obtained with the A7 smooth muscle line. These data suggest that the skeletal muscle activity which inhibits cell-substratum adhesion of PC12 cells is structurally different from the adhesion-promoting activities of smooth muscle.

Glycosaminoglycan and protein composition of adherons. The $16 \mathrm{~S}$ adheron from $\mathrm{L} 6$ myoblasts consists of a mixture of several glycosaminoglycans and proteins, including fibronectin and collagen (Schubert and LaCorbiere, 1980a). Since fibronectin inhibits cell-substratum adhesion of PC12 cells (Fig. 4), it was possible that the difference between adherons of skeletal and smooth muscle may be the lack of fibronectin in the smooth muscle preparation. Alternatively, variations in the GAG 
or other protein composition may be responsible for the differences in activity. To assay the protein and GAG compositions of the adhesion-modulating particles from ¿wo skeletal muscle and two smooth muscle cell lines, the cells were labeled for $16 \mathrm{hr}$ with $\left[{ }^{3} \mathrm{H}\right]$ - or $\left[{ }^{14} \mathrm{C}\right] l e u c i n e$, $\left[{ }^{3} \mathrm{H}\right]$ glucosamine, or ${ }^{35} \mathrm{SO}_{4}$ in serum-free medium. The culture medium then was centrifuged at $100,000 \times g$ for $2 \mathrm{hr}$, and the pellets were washed twice and sedimented on sucrose gradients as shown in Figure 6. The isotopically labeled peaks were removed, the sucrose was diluted with HEPES medium, and the particles were re-pelleted by centrifugation overnight at $100,000 \times g$. These pellets were assayed for proteins on polyacrylamide gels and the GAG content was determined by column chromatography and enzymatic analysis. When the leucine-labeled material was electrophoresed on a sodium dodecyl sulfate (SDS)-acrylamide gel system which readily separates fibronectin and the collagens, the protein composition of the particles from the two types of muscle cells was very similar (Fig. 7). $\mathrm{BC}_{3} \mathrm{H} 1$ contained proteins which comigrated with L6 fibronectin ( peak $A$ ) and the collagens (peaks $B$ and $C$; see also Schubert and LaCorbiere, $1980 \mathrm{a}, \mathrm{c}) . \mathrm{BC}_{3} \mathrm{H} 1$ fibronectin was identified further by its specific precipitation with anti-rat cold-insoluble globulin and a positive reaction on Ouchterlony plates between $\mathrm{BC}_{3} \mathrm{H1}$ adherons and anti-fibronectin. Similar results were obtained when the proteins of A10 and B44 particles were compared with those of L6. It is possible, however, that peak $A$ of smooth muscle is not fibronectin but a protein of similar size and antigenicity. These data suggest that the presence of fibronectin per se in skeletal muscle adherons is not responsible for the inhibition of PC12 cell-substratum adhesion.
In contrast to the fibronectin and collagen composition of the adherons from the four cell lines, the GAGs in the various muscle clones were different. Figure 8 shows the elution profile from a DEAE column of GAGs prepared from the adherons of B44 myoblasts and A10 smooth muscle cells. The GAG analysis of $\mathrm{L} 6$ adherons was published previously (Schubert and LaCorbiere, 1980a). Four classes of GAGs were separated, and each peak of radioactivity was identified by enzymatic degradation. Peak $B$ in both cell lines was degraded by chondroitinase $\mathrm{ABC}$ and testicular hyaluronidase but not by nitrous acid or fungal hyaluronidase. It was therefore chondroitin. Peak $C$ contained sulfate and was degraded by nitrous acid but not by fungal hyaluronidase. It was identified as heparan sulfate. Peak $D$ also contained sulfate and was degraded by chondroitinase $\mathrm{ABC}$ but not by nitrous acid. It was chondroitin sulfate. Peak A of B44 was degraded completely by fungal hyaluronidase but not by nitrous acid. It was identified as hyaluronic acid. Finally, peaks $A_{1}$ and $A_{2}$ of $\mathrm{BC}_{3} \mathrm{H} 1$ were degraded by none of the above reagents and therefore must be glycopeptides, mucins, or a GAG of unknown composition. The GAG composition in the adherons from two skeletal muscle and two smooth muscle cell lines is shown in Table II. There was a distinct difference between the smooth muscle and skeletal muscle cell adhesion-mediating particles, for only those of skeletal muscle contain hyaluronic acid.

\section{Discussion}

The following data suggest that there is some adhesive specificity associated with the extracellular glycoprotein particles (adherons) of muscle. (1) Adherons from skeletal muscle inhibit the cell-substratum adhesion of the

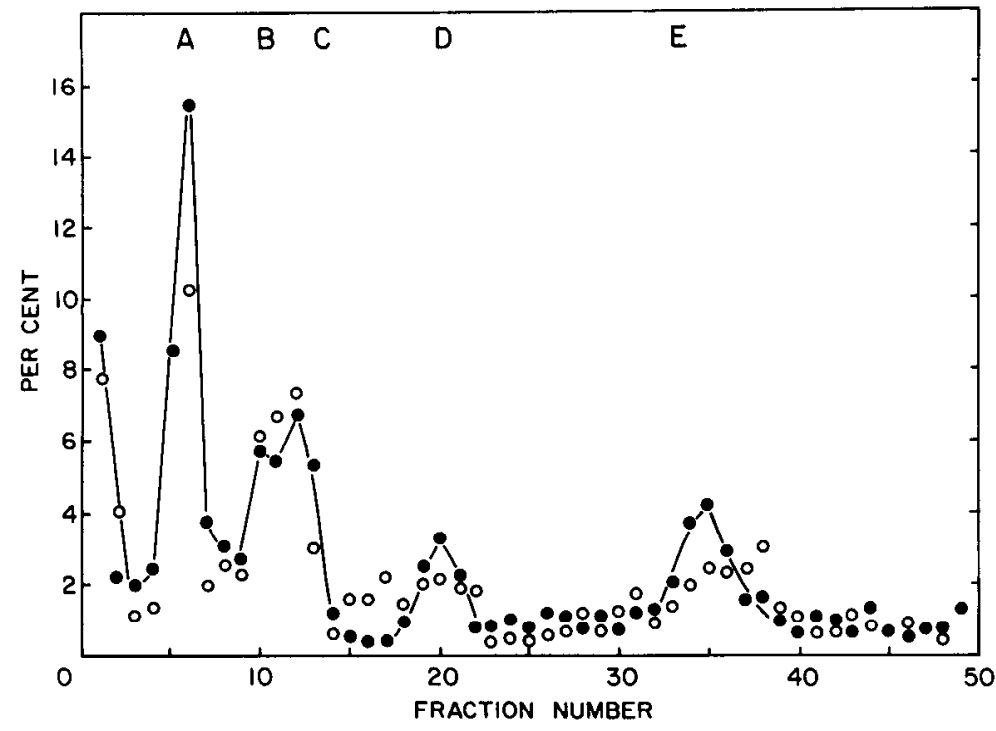

Figure 7. SDS-acrylamide gels of adheron proteins from $\mathrm{L} 6$ and $\mathrm{BC}_{3} \mathrm{H} 1$. Exponentially dividing cells were labeled with $\left[{ }^{3} \mathrm{H}\right]$ leucine or $\left[{ }^{14} \mathrm{C}\right]$ leucine for $18 \mathrm{hr}$ and the culture supernatant was centrifuged $(100,000 \times g$ for $2 \mathrm{hr}$ ). The pellet then was sedimented on a 5 to $20 \%$ sucrose gradient as described in Figure 6 . The peaks were isolated and electrophoresed in $6 \%$ polyacrylamide gels containing SDS. The data are presented as the percentage of the total counts recovered in the gel at each point. The results were the same when the label was reversed. - $\left[{ }^{3} \mathrm{H}\right]$ Leucine $\mathrm{BC}_{3} \mathrm{H} 1 ; O,\left[{ }^{14} \mathrm{C}\right]$ leucine L6. 


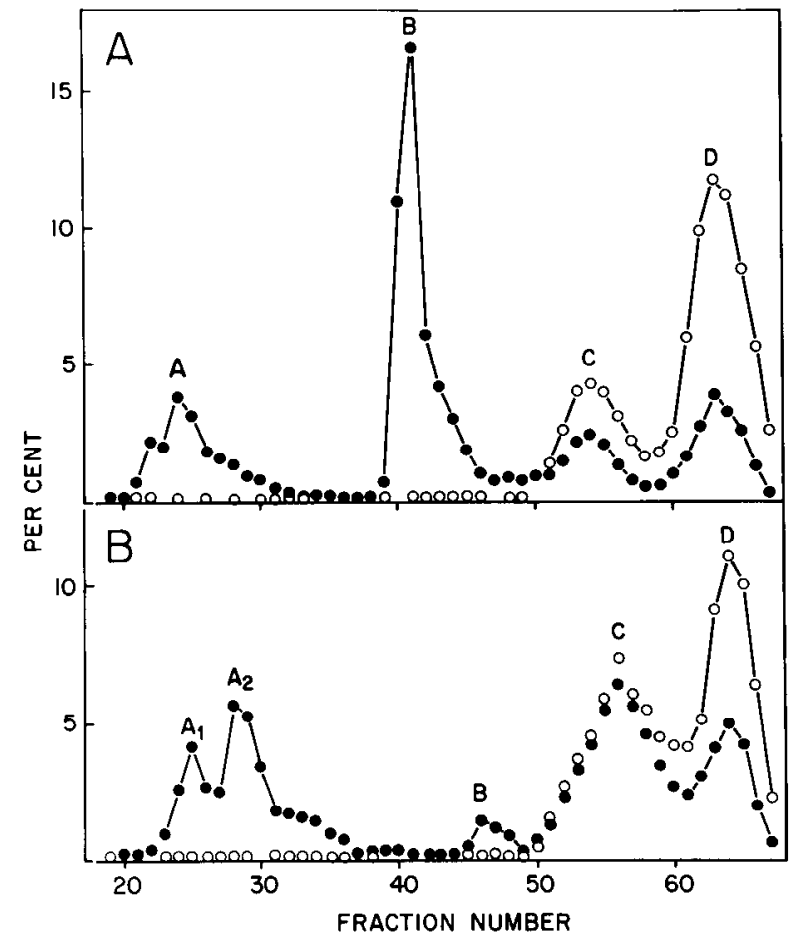

Figure 8. Elution profile of GAGs from B44 and A10 particles. Exponentially dividing cells were labeled with $\left[{ }^{3} \mathrm{H}\right]$ glucosamine and ${ }^{35} \mathrm{SO}_{4}$ for $18 \mathrm{hr}$ and the culture medium supernatant was centrifuged $(100,000 \times g$ for $2 \mathrm{hr})$. The pellet was applied to a 5 to $20 \%$ sucrose gradient in the absence of calcium. The peaks were isolated and digested with pronase, and the GAGs were run on a $1 \times 20 \mathrm{~cm} \mathrm{DE-52} \mathrm{column} \mathrm{(DE-52,} \mathrm{Whatman,} \mathrm{England).}$ The starting buffer was $0.002 \mathrm{M}$ Tris, $\mathrm{pH} 7.5,0.01 \mathrm{M} \mathrm{NaCl}$, and the GAGs were eluted with a linear gradient between 0.01 and $1.0 \mathrm{M} \mathrm{NaCl}$ in $0.002 \mathrm{M}$ Tris, $\mathrm{pH} 7.5$, followed by a wash with 5 $\mathrm{M} \mathrm{NaCl}$. The data are expressed as the percentage of the total recovered counts in each fraction. $O,\left[{ }^{35} \mathrm{~S}\right]$ Sulfate label; $O$, $\left[{ }^{3} \mathrm{H}\right]$ glucosamine label. $A, \mathrm{~B} 44 ; B, \mathrm{~A} 10$.

PC12 sympathetic-like nerve cell line, while adherons from smooth muscle promote cell-substratum adhesion of PC12 cells (Figs. 1, 3, 4, and 6). (2) Antibodies prepared against L6 myoblast adherons block skeletal muscle myoblast adhesion to skeletal muscle adherons but not PC12 cell adhesion to smooth muscle adherons (Fig. 5). (3) The particles from skeletal and smooth muscle have different sedimentation values in calcium-free sucrose gradients (Fig. 6). (4) The GAG composition of each adheron class is also distinct. (5) The type of GAGs which inhibit the adhesion of $\mathrm{PC} 12$ cells to adherons prepared from three smooth muscle cell lines is similar (Table I), suggesting the involvement of GAGs in the adhesion process.

The mechanisms of cell-cell interactions in the nervous system are still unresolved. The only adhesion-mediating molecules from the nervous system which have been characterized are two proteins from the chick neural retina. McClay and Moscona (1974) initially described an activity which aggregates embryonic neural retina cells, and this has been purified from growth-conditioned culture medium and cell membranes on the basis of its cellaggregating activity (Hausman and Moscona, 1975, 1976). It is a protein of approximately 50,000 molecular weight. In contrast, a protein of 140,000 molecular weight also
TABLE II

GAG composition of adherons from skeletal and smooth muscle cell lines

The data are presented as the percentage of the total $\left[{ }^{3} \mathrm{H}\right]$ glucosamine-labeled material in the particles which is separable into each GAG by chromatography on DEAE-cellulose columns. The GAGs were identified as follows: the GAGs associated with ${ }^{35} \mathrm{SO}_{4}$ and $\left[{ }^{3} \mathrm{H}\right]$ glucosamine-labeled peaks from sucrose gradients were digested with pronase and chromatographed on a DEAE-cellulose column to separate the classes of GAGs. The material in the individual peaks was treated with enzymes and degradation was assayed on G-50 columns (Schubert and LaCorbiere, 1980b). The capital letters following the GAG identification refer to the peaks in Figure 8.

\begin{tabular}{|c|c|c|c|c|}
\hline GAG & L6 & B44 & $\mathrm{BC}_{3} \mathrm{Hl}$ & A10 \\
\hline Unknown $\left(A \cdot\right.$ and $\left.A_{2}\right)$ & N.D..$^{a}$ & N.D. & 8 & 30 \\
\hline Hyaluronic acid $(A)$ & 18 & 21 & N.D. & N.D. \\
\hline Chondroitin $(B)$ & 49 & 46 & 42 & 5.3 \\
\hline Heparan sulfate $(C)$ & 4 & 12 & N.D. & 18 \\
\hline Chondroitin sulfate $(D)$ & 30 & 16 & 44 & 37 \\
\hline Heparin & N.D. & N.D. & N.D. & N.D. \\
\hline
\end{tabular}

${ }^{a}$ N.D., not detectable or less than $0.5 \%$ of the total secreted GAGs.

was isolated from growth-conditioned medium of retina cells on the basis of its ability to neutralize antibodies which block retina cell aggregation (Thiery et al., 1977). Both proteins are apparently present on the surface of most nerve cells. It is possible that these proteins are constituents of large glycoprotein complexes similar to those described above.

The above data show that the adherons from skeletal and smonth muscle can be distinguished on the basis of their interactions with the sympathetic nerve-like cell line $\mathrm{PC} 12$, their response to a specific antiserum, their inhibition of cell-substratum adhesion by GAGs, their relative sedimentation value in calcium-free sucrose gradients, and their GAG compositions. These characteristics must be a reflection of differences in the structure of the smooth and skeletal muscle particles. An examination of the protein content of adherons from muscle cell lines of each type failed to identify a systematic compositional difference. Since fibronectin alone inhibits the cell-substratum interaction of PC12 cells (Fig. 4) and since all of the skeletal muscle particles contained a fibronectin-like molecule (Fig. 7; Schubert and LaCorbiere, 1980a), it was possible that the presence of fibronectin per se was sufficient to inhibit PC12 adhesion. This was not the case, however, for particles from smooth muscle promoted the adhesion of $\mathrm{PC} 12$ and contained as much fibronectin as the skeletal muscle particles (Fig. 7). The collagen content of the smooth and skeletal muscle particles was also similar. The other major constituents of the muscle particles are the GAGs (Table II). There was a systematic difference between GAGs of smooth and skeletal muscle adherons, for only the skeletal muscle particles contained hyaluronic acid. However, unless it can be shown that hyaluronic acid alone is responsible for the adhesive differences, two additional alternatives remain; none have been ruled out: either an unidentified GAG or protein is responsible for the adhesive differences or it is the combination of two or more components which produces the two adhesive classes. Finally, it must be stressed that only skeletal muscle adherons inhibit the adhesion of PC12 cells. Smooth muscle cells and all 
other cell types tested promoted PC12 adhesion to varying extents. This shows that the properties of adherons from skeletal muscle constitute a minor subset of those from all cells with respect to the adhesion of PC12 cells. Skeletal muscle adherons do, however, promote the adhesion of other cell types, such as skeletal muscle myoblasts (Schubert and LaCorbiere, 1980a).

The adhesion-modulating activity described in this paper could influence the innervation of embryonic muscles in two ways. Since the adheron is released in a soluble form from cells, it may diffuse a small distance away from the muscle and attach to the surface of surrounding cells or to basement membrane. GAG particles 10 to $20 \mathrm{~nm}$ in diameter are spaced evenly along the outer surfaces of some basal lamina (Hay, 1978). In the case of smooth muscle cells, adherons may form a limited adhesion gradient to "guide" incoming sympathetic axons. This substratum would have to be more adhesive for sympathetic nerve cell growth cones than that generated by neighboring tissues. In contrast, particles from skeletal muscle could establish an inhibitory gradient around that tissue for sympathetic nerve. For this extrapolation from in vitro data to the developing animal to be valid, the adhesive properties of whole cells must be reflected in the adhesion of the growth cone. There is evidence for this, for the adhesive properties of sympathetic nerve cell bodies and the directional turning response of growth cones are affected in a similar way by exogenous nerve growth factor, calcium ions, and cyclic nucleotides (Schubert et al., 1978; Gundersen and Barrett, 1980). Once the axon terminals are near the smooth muscle target, a high density of adhesion-promoting particles either on the surface of the cell or in its extracellular matrix may physically stabilize the nerve-muscle contact.

\section{References}

Bloch, R., and B. Geiger (1980) The localization of acetylcholine receptor clusters in areas of cell-substrate contact in cultures of rat myotubes. Cell 21: 25-35.

Brackenbury, R., J. P. Thiery, U. Rutishauser, and G. Edelman (1977) Adhesion among neural cells of chick embryo. J. Biol. Chem. 252: 6385-6392.

Collins, F. (1980) Neurite outgrowth induced by substrate associated material from non-neuronal cells. Dev. Biol. 79: 247252.

Culp, L. A. (1974) Substrate-attached glycoproteins mediating adhesion of normal and virus-transformed mouse fibroblasts. J. Cell Biol. 63: 71-83.

Garvey, J., N. Cremer, and D. Sussdorf, eds. (1977) Methods in Immunology, Academic Press, New York.

Greene, L., and M. Tischler (1976) Establishment of a noradrenergic clonal line of rat adrenal pheochromocytoma cells which respond to nerve growth factor. Proc. Natl. Acad. Sci. U. S. A. 75: 4587-4591.
Gundersen, R. W., and J. N. Barrett (1980) Characterization of the turning response of dorsal root neurites toward nerve growth factor. J. Cell Biol. 87: 546-554.

Hausman, R. E., and A. A. Moscona (1975) Purification and characterization of retina-specific cell aggregating factor. Proc. Natl. Acad. Sci. U. S. A. 72: 916-920.

Hausman, R. E., and A. A. Moscona (1976) Isolation of retinaspecific cell-aggregating factor from membranes of embryonic neural retina tissue. Proc. Natl. Acad. Sci. U. S. A. 73: 35943598.

Hay, E. D. (1978) Role of basement membranes in development and differentiation. In Biology and Chemistry of Basement Membranes, N. A. Kefalides, ed., pp. 119-136, Academic Press, New York.

Kimes, B., and B. Brandt (1976) Characterization of two putative smooth muscle cell lines from rat thoracic aorta. Exp. Cell Res. 98: 349-366.

McClay, D. R., and A. A. Moscona (1974) Purification of the specific cell-aggregating factor from embryonic neural retina cells. Exp. Cell Res. 87: 438-441.

Millis, A., and M. Hoyle (1978) Fibroblast-conditioned medium contains cell surface proteins required for cell attachment and spreading. Nature 271: 668-670.

Moore, E. G. (1976) Cell to substratum adhesion promoting activity released by normal and virus-transformed cells in culture. J. Cell Biol. 70: 634-647.

Saito, H., T. Yamagato, and S. Suzuki (1968) Enzymatic methods for the determination of small quantities of isomeric chondroitin sulfates. J. Biol. Chem. 243: 1536-1546.

Schubert, D., and M. LaCorbiere (1980a) Role of a 16S glycoprotein complex in cellular adhesion. Proc. Natl. Acad. Sci. U. S. A. 77: 4137-4141.

Schubert, D., and M. LaCorbiere (1980b) A role of secreted glycosaminoglycans in cell-substratum adhesion. J. Biol. Chem. 255: 11564-11569.

Schubert, D., and M. LaCorbiere (1980c) Altered collagen and glycosaminoglycan secretion by a skeletal muscle myoblast variant. J. Biol. Chem. 255: 11557-11563.

Schubert, D., A. J. Harris, C. E. Devine, and S. Heinemann (1974a) Characterization of a unique muscle cell line. J. Cell Biol. 61: 398 .

Schubert, D., S. Heinemann, W. Carlisle, H. Tarikas, B. Kimes, J. Patrick, J. H. Steinbach, W. Culp, and B. Brandt (1974b) Clonal cell lines from the rat central nervous system. Nature 249: 224-227.

Schubert, D., M. LaCorbiere, C. Whitlock, and W. Stallcup (1978) Alterations in the surface properties of cells responsive to nerve growth factor. Nature 273: 718-723.

Thiery, J., R. Brackenbury, U. Rutishauser, and G. Edelman (1977) Adhesion among neural cells of chick retina. J. Biol. Chem. 252: 6841-6845.

Underhill, C. B., and J. M. Keller (1976) Density-dependent changes in the amount of sulfated glycosaminoglycans associated with mouse 3T3 cells. J. Cell Physiol. 89: 53-64.

Yaffe, D. (1968) Retention of differentiation potentialities during prolonged cultivation of myogenic cells. Proc. Natl. Acad. Sci. U. S. A. 61 : 477-481. 